\title{
Morphological diversification in different trematode lineages : body size, host type, or time?
}

\author{
R. POULIN* \\ Department of Zoology, University of Otago, P.O. Box 56, Dunedin 9054, New Zealand
}

(Received 30 Fuly 2008; revised 2 September 2008; accepted 3 September 2008)

\begin{abstract}
SUMMARY
Different lineages experience different rates of phenotypic diversification, resulting in greater or lower variance in the expression of phenotypic traits among the species within a lineage. Here, morphological diversification is investigated in 14 different trematode families, based on a dataset comprising morphometric data on body size and 4 anatomical structures (oral sucker, ventral sucker, pharynx, cirrus sac) from 386 species. Three hypotheses are tested and subsequently rejected based on the empirical evidence. First, the degree of morphological variation in all traits within a trematode family, measured as the coefficient of variation among species, appears independent of the average body size of species belonging to that family. Second, patterns of morphological diversification appear similar whether endothermic or ectothermic vertebrates are used as definitive hosts. Third, phylogenetically older trematode lineages did not display greater morphological variation than younger, more derived ones, ruling out evolutionary time as an explanation. The results are consistent with developmental constraints acting on morphological diversification, since for some pairs of traits, variation in one trait is not independent of variation in another trait. More importantly, across most families, variation in body size was significantly more pronounced than variation in the relative sizes of the other morphological features. Trematode body size therefore varies widely while the general body architecture of the family is maintained. The fact that the evolution of the body plan is more conservative than that of body size suggests that the range of morphologies that can evolve in trematodes is constrained.
\end{abstract}

Key words: body plan, coefficient of variation, phenotypic diversity, trematodes.

\section{INTRODUCTION}

Phenotypic diversification, or the variance in the expression of phenotypic traits among a group of species, can differ substantially between lineages, even between lineages that are closely related (Foote, 1997; Carroll, 2001). Several hypotheses suggest a link between differences in the biology or ecology of distinct lineages and the rate of evolution of morphological or other phenotypic characters within these lineages (Foote, 1997; O’Meara et al. 2006; Wainwright, 2007). For instance, greater phenotypic diversification may result from the invasion of a novel habitat, the appearance of a key innovation, strong effects from community interactions or environmental factors, weak developmental constraints acting on the body plan, or simply from longer evolutionary time (e.g. Warheit et al. 1999; Lovette et al. 2002; Collar et al. 2005; Gavrilets and Vose, 2005 ; O’Meara et al. 2006; Ricklefs, 2006). However, there have been relatively few empirical tests of these hypotheses, and these have not extended to a broad range of taxonomic groups.

\footnotetext{
* Corresponding author. Tel: +643479 7983. Fax: +643479 7584. E-mail: robert.poulin@stonebow.otago. ac.nz
}

As a case in point, there have been no studies of the determinants of phenotypic diversification in parasitic groups, even though parasitism has arisen at least 60 independent times as a mode of life, and many of these transitions have been followed by radiations (Poulin and Morand, 2004; Poulin, 2007). Within all major groups of endohelminth parasites of vertebrates (i.e. trematodes, cestodes, acanthocephalans, nematodes), several different families live within the host's gastrointestinal tract, and many of them represent separate colonizations of this habitat. Given the common habitat of these different lineages, one might expect that they would show similar rates of phenotypic diversification. However, there are at least 3 factors that can cause morphological characters to diversify unequally among related parasite families. First, morphological diversification may be size-dependent, and differ between families consisting of species with generally large body size and those with smaller body sizes. The perception of habitat heterogeneity depends on scale, with small organisms achieving a higher resolution of environmental grain than large ones. Just as body size plays a role in determining species diversification in natural communities (Morse et al. 1985; Siemann et al. 1996; Ritchie and Olff, 1999), it may affect morphological diversification within lineages. Therefore, 
because perceived environmental heterogeneity is greater for smaller parasites, one might expect smallbodied families to display greater morphological variation.

Second, there may be different selective pressures acting on the evolution of morphological traits in parasites of endothermic vertebrate hosts (birds and mammals) than in parasites of ectotherms (teleost fishes, amphibians and reptiles). For gastrointestinal parasites, these two types of hosts provide habitats with different characteristics. The frequency of peristaltic movements and the amounts of food passing through the gastrointestinal tract of endotherms are generally greater than in ectotherms, possibly influencing the evolution of attachment structures. The microstructure of the gut wall also tends to be more complex, with more folds, villi and microvilli, in endotherms than in ectotherms (Kardong, 2005). Finally, parasite communities living in the gut of endothermic vertebrates generally consist of more species and more total individuals than their counterparts in ectotherms (Bush et al. 1990; Poulin, 1995 ; Poulin and Morand, 2004), thus favouring strong pressures from competitive interactions. All these characteristics may favour greater morphological diversification among parasite lineages of endothermic hosts than those of ectothermic hosts.

Third, evolutionary time may matter as well, and phylogenetically older lineages may display greater morphological variation (see Collar et al. 2005; Ricklefs, 2006). The hypothesis that time of independent evolution accounts for most differences in extant morphological diversity among lineages needs to be addressed, since it is possibly the most parsimonious explanation. In the absence of precise information on the age of various lineages, it is still possible to use phylogenetic data to identify basal and derived taxa, i.e. taxa that have originated at different distances from the base of the tree (see Pagel, 1997, 1999, 2002; Knouft and Page, 2003). This approach can give an indication of how morphological traits have diversified along ancient and recent branches in the same phylogenetic tree.

Here, morphological diversification is investigated in different trematode families. Trematodes (hereafter, specifically the subclass Digenea) are parasitic flatworms that almost all use vertebrates as definitive hosts. Most taxa considered here live within the host's gastrointestinal tract, where they attach using oral and/or ventral suckers and feed either on host gut contents or on host blood and mucus. The specific objectives of this study are to: (i) determine whether variation in one morphological trait is independent of variation in other traits, and whether some traits display consistently greater variation than others among the different trematode families; (ii) assess whether morphological variation in trematodes is dependent on body size; (iii) determine whether the type of host used influences patterns of morphological diversification in trematodes; and (iv) test whether morphological variation among species within a family is generally greater in basal (older) than in derived (younger) lineages. Only a subset of trematode families could be included here, because of limited availability of data; however, these were sufficient to test the above hypotheses. This study does not aim to characterize morphological variation across the full spectrum of trematodes, but instead it assesses the role, if any, of three specific processes involved in morphological diversification.

\section{MATERIALS AND METHODS}

Data were compiled from original species descriptions published in all issues of Fournal of Parasitology (volumes 44 to 93) and Systematic Parasitology (volumes 36 to 69) available electronically at the University of Otago. While these do not cover the whole range of trematode species in existence, they nevertheless provide a representative sample of the existing variation in body morphometrics within the group. The taxonomy proposed in the original sources was generally accepted, although several taxa were cross-checked with the recent classification proposed by Gibson et al. (2002) and Jones et al. (2005). Only data on adult worms were included. Measurements used here are either the means or the mid-point of ranges based on the examination of several specimens per species. For each species, 2 measures of body size were used: (i) body length, and (ii) body surface area. Although trematodes are not necessarily flattened, only 2 dimensions are reported in species descriptions (body length and width); thus, the surface area of a 2-dimensional projection was used as the best estimate one can get of trematode body size. Their surface area was estimated using the formula for an ellipsoid, $(\pi L W) / 4$, where $L$ and $W$ are the length and width of the worm, respectively.

In addition to body size, the lengths (or widths, in the few cases where width exceeded length) of 4 other structures were also recorded for each species: (i) the oral sucker; (ii) the ventral sucker, or acetabulum; (iii) the pharynx, a muscular structure serving to pump food in through the mouth; and (iv) the cirrus sac, the terminal portion of the male reproductive system which houses an intromittent organ (Galaktionov and Dobrovolskij, 2003). Species in the family Bucephalidae lack an oral sucker, and instead possess an anterior organ known as the rhynchus; although the homology of this structure with the oral sucker is debatable, its dimensions are here used in place of those of a true sucker. These are 4 morphological features possessed by most trematode species and for which data are routinely provided in species descriptions. For each species, the size of these structures is expressed as the ratio of the 
structure's size to body length, in order to correct for body size differences between species. Hereafter, the sizes of these structures always refer to these relative measures and not to absolute sizes.

For each of the 6 morphological measurements considered here (body length, body surface area, size of oral sucker, size of ventral sucker, pharynx size, and size of cirrus sac), and within each trematode family, the coefficient of variation (CV) was calculated across species. These coefficients represent the standard deviation in trait values expressed as a percentage of the mean value, and they are used as a measure of morphological variation. For each of the 6 traits, a Pearson's product-moment correlation was computed across families between $\mathrm{CV}$ and the number of species used to compute the $\mathrm{CV}$, to test for any potential confounding influence of the number of species included on estimates of variation.

Values of CV for different traits were compared to each other, in a pair-wise manner taking family identity into account, using two-tailed paired $t$-tests. Also, possible pair-wise relationships between the values of $\mathrm{CV}$ for different measurements across families were tested using Pearson's product-moment correlation coefficients.

Values of $\mathrm{CV}$ for the 6 different traits were correlated across families, using Pearson's productmoment correlation coefficients, with 2 measures of average family body size: mean body length, and mean body surface area, both computed across all species in a family for which data were available. This was used to test whether morphological variation in trematodes is size dependent.

One-way ANOVAs were used to compare CV values between families exploiting endothermic definitive hosts and those using ectotherms, separately for each of the 6 morphological traits. In addition, to account for potential phylogenetic influences, these comparisons were repeated using phylogenetically independent contrasts (Felsenstein, 1985) computed on log-transformed data. Each family using endothermic hosts was paired with the most closely related family using ectotherms, based on the trematode phylogeny of Olson et al. (2003), with no family being used in more than one contrast. For each of the 6 traits, contrasts in CV values were compared with 0 , the contrast value expected under the null hypothesis of no difference, using one-group two-tailed $t$-tests.

To test whether morphological variation among species within a family is generally greater in basal than in derived lineages, all $\mathrm{CV}$ values were logtransformed prior to analysis. Evolutionary trends in morphological variation were examined separately for each of the 6 traits using a generalised least squares regression (GLS). This allows one to determine whether variation in one trait correlates with clade rank among families within a group (Pagel, 1997, 1999, 2002; Knouft and Page, 2003). Clade rank is not equivalent to taxonomic rank; instead, it is the number of branching or speciation events between an extant family and the root of a phylogenetic tree, the root being the bifurcation from which all taxa in the group have descended (Norell and Novacek, 1992; Knouft and Page, 2003). Clade rank quantifies the evolutionary position of a family within a clade, or the total path length from the root of the tree to a given family: basal families are taxa with the lowest rank, and derived families have the highest rank. Although data on morphology were not available for all families in the trematode phylogeny used (Olson et al. 2003), all families were included in the computations of clade ranks and in the GLS model, to obtain accurate phylogenetic information. Morphological variation for each family is predicted from the GLS regression of CV values on clade rank, i.e. on the distance from the root of the phylogeny to the family (Pagel, 1997, 1999, 2002; Knouft and Page, 2003). In this directional model of evolution, the slope defines the phylogenetically correct slope of the line relating clade rank to log-transformed CV values (Pagel, 1997, 1999, 2002; Knouft and Page, 2003). Precise information on branch length was not available, and all branches within a clade were set equal; this places a constraint on the evolutionary model, where most of the divergence in $\mathrm{CV}$ values between sister taxa must be assumed to take place at, and not between, speciation events. To verify that this punctuational assumption is realistic, rough estimates of branch lengths were derived from the species-level phylograms of Olson et al. (2003), and used in preliminary regressions instead of clade rank; the results (not shown here) are all consistent with analyses using clade rank. A likelihood-ratio (LR) test statistic was used to assess the probability that the GLS directional model was a better predictor of morphological evolution within a clade than a null, or random walk, model in which the slope of the $\mathrm{CV}$-versus-clade rank relationship equals zero. In the test, $\mathrm{LR}=-2 \log \left(H_{0} / H_{1}\right)$, where $H_{0}$ is the likelihood associated with the null hypothesis and $H_{1}$ is the likelihood associated with the directional hypothesis (Pagel, 1997, 1999). The significance of the test is determined by comparing LR to a $X^{2}$ statistic with D.F. $=1 \quad($ alpha $=0 \cdot 05)$. The test was implemented using the program Continuous within the Bayes'Traits package (available at http://www. evolution.rdg.ac.uk/Bayes'Traits.html).

\section{RESULTS}

Only families for which data were available for at least 12 species were included here. Sufficient data were obtained for 14 different trematode families, including a total of 386 species and 228 genera (Table 1); the complete dataset is available freely from the author upon request or as Supplementary Material Online from the journal's website (http:// 
Table 1. Coefficients of variation (CV) among species for 6 morphological traits within 14 trematode families

\begin{tabular}{|c|c|c|c|c|c|c|c|c|}
\hline Family & $\begin{array}{l}\text { Normal } \\
\text { definitive } \\
\text { host }\end{array}$ & $\begin{array}{l}\text { No. of } \\
\text { species } \\
\text { (genera) }\end{array}$ & $\begin{array}{l}\text { Body } \\
\text { length }\end{array}$ & $\begin{array}{l}\text { Body } \\
\text { surface } \\
\text { area }\end{array}$ & $\begin{array}{l}\text { Oral } \\
\text { sucker }\end{array}$ & $\begin{array}{l}\text { Ventral } \\
\text { sucker }\end{array}$ & Pharynx & $\begin{array}{l}\text { Cirrus } \\
\text { sac }\end{array}$ \\
\hline Allocreadiidae & Ectotherm & $13(11)$ & $60 \cdot 7$ & $125 \cdot 2$ & $34 \cdot 7$ & $46 \cdot 4$ & $29 \cdot 6$ & $71 \cdot 0$ \\
\hline Bucephalidae & Ectotherm & $32(11)$ & $55 \cdot 6$ & $98 \cdot \overline{5}$ & $56 \cdot 3$ & - & $57 \cdot 1$ & $31 \cdot 7$ \\
\hline Cryptogonimidae & Ectotherm & $28(17)$ & $112 \cdot 9$ & $97 \cdot 5$ & $61 \cdot 6$ & $54 \cdot 2$ & $57 \cdot 1$ & - \\
\hline Dicrocoeliidae & Endotherm & $22(11)$ & $37 \cdot 0$ & $98 \cdot 3$ & $59 \cdot 2$ & $62 \cdot 7$ & $43 \cdot 8$ & $46 \cdot 9$ \\
\hline Echinostomatidae & Endotherm & $29(18)$ & $83 \cdot 8$ & $111 \cdot 3$ & $72 \cdot 1$ & $52 \cdot 3$ & $55 \cdot 8$ & $58 \cdot 7$ \\
\hline Fellodistomidae & Ectotherm & $24(17)$ & $78 \cdot 5$ & $131 \cdot 3$ & $39 \cdot 1$ & $63 \cdot 1$ & $45 \cdot 5$ & $50 \cdot 0$ \\
\hline Hemiuridae & Ectotherm & $27(19)$ & $100 \cdot 5$ & $269 \cdot 6$ & $40 \cdot 1$ & $43 \cdot 5$ & $31 \cdot 0$ & - \\
\hline Heterophyidae & Endotherm & $15(7)$ & $114 \cdot 4$ & $267 \cdot 7$ & $44 \cdot 5$ & $44 \cdot 9$ & $29 \cdot 5$ & - \\
\hline Lecithodendriidae & Endotherm & $16(13)$ & $65 \cdot 0$ & $127 \cdot 5$ & $42 \cdot 3$ & $46 \cdot 2$ & $40 \cdot 4$ & $51 \cdot 6$ \\
\hline Lepocreadiidae & Ectotherm & $73(44)$ & $61 \cdot 0$ & $81 \cdot 3$ & $52 \cdot 7$ & $83 \cdot 3$ & $59 \cdot 2$ & $59 \cdot 0$ \\
\hline Macroderoididae & Ectotherm & $18(9)$ & $65 \cdot 3$ & $92 \cdot 4$ & $54 \cdot 9$ & $58 \cdot 9$ & $45 \cdot 3$ & $45 \cdot 4$ \\
\hline Microphallidae & Endotherm & $23(12)$ & $52 \cdot 5$ & $101 \cdot 0$ & $32 \cdot 0$ & $28 \cdot 7$ & $33 \cdot 6$ & $64 \cdot 0$ \\
\hline Opecoelidae & Ectotherm & $45(25)$ & $64 \cdot 3$ & $124 \cdot 1$ & $50 \cdot 0$ & $54 \cdot 3$ & $56 \cdot 2$ & $57 \cdot 7$ \\
\hline Plagiorchiidae & Ectotherm & $21(14)$ & $78 \cdot 6$ & $116 \cdot 1$ & $47 \cdot 6$ & $63 \cdot 4$ & $36 \cdot 0$ & $56 \cdot 2$ \\
\hline
\end{tabular}

Table 2. Pair-wise comparisons between the coefficients of variation (CV) for 6 morphological traits

(Comparisons, two-tailed paired $t$-tests, above the diagonal; and pair-wise relationships among these CV, Pearson productmoment correlation coefficients, below the diagonal.)

\begin{tabular}{|c|c|c|c|c|c|c|}
\hline & Body length & $\begin{array}{l}\text { Body surface } \\
\text { area }\end{array}$ & Oral sucker & Ventral sucker & Pharynx & Cirrus sac \\
\hline Body length & - & $t_{13}=4 \cdot 445^{* *}$ & $t_{13}=3 \cdot 719 * *$ & $t_{12}=2 \cdot 660^{*}$ & $t_{13}=4 \cdot 101 * *$ & $t_{9}=1.759$ \\
\hline Body surface area & $0.633^{*}$ & - & $t_{13}=4.766 * *$ & $t_{12}=4 \cdot 249 * *$ & $t_{13}=4 \cdot 854 * *$ & $t_{9}=9 \cdot 898^{* *}$ \\
\hline Oral sucker & $0 \cdot 073$ & $-0 \cdot 352$ & - & $t_{12}=1 \cdot 511$ & $t_{13}=2 \cdot 162^{*}$ & $t_{9}=1 \cdot 422$ \\
\hline Ventral sucker & $-0 \cdot 165$ & $-0 \cdot 402$ & $0 \cdot 447$ & - & $t_{12}=3 \cdot 496 * *$ & $t_{9}=0 \cdot 020$ \\
\hline Pharynx & $-0 \cdot 044$ & $-0 \cdot 548^{*}$ & $0.735 * *$ & $0 \cdot 214$ & - & $t_{9}=2 \cdot 513^{*}$ \\
\hline Cirrus sac & $0 \cdot 178$ & $0 \cdot 267$ & $-0 \cdot 419$ & $-0 \cdot 376$ & $-0 \cdot 451$ & - \\
\hline
\end{tabular}

* $P<0.05 ; * * P<0 \cdot 005$.

journals.cambridge.org/PAR). Five of these families use endothermic vertebrates as definitive hosts, whereas the rest use ectotherms. Note that no data are available for the ventral sucker or cirrus sac in some families (see Table 1), because these families lack these particular structures.

The species within the dataset show considerable variation in all recorded dimensions; for instance, there is a more than 300 -fold difference in body surface area between the smallest and largest species. Within families, there is also substantial variability among species as indicated by the coefficients of variation $(\mathrm{CVs})$ for all 6 measurements investigated here (Table 1). For pharynx size, there is a significant correlation across families between $\mathrm{CV}$ and the number of species used to estimate it $(r=0.638$, $N=14, P=0 \cdot 014)$. There were no such correlations for the other 5 variables (all $P>0 \cdot 29$ ), and for them estimates of $\mathrm{CV}$ are thus independent of how many species were included. To obtain a similarly independent measure for pharynx size, the residuals of a regression of $\mathrm{CV}$ in pharynx size against number of species were used instead of 'raw' $\mathrm{CV}$ values in the subsequent analyses (except the paired $t$-tests that follow).

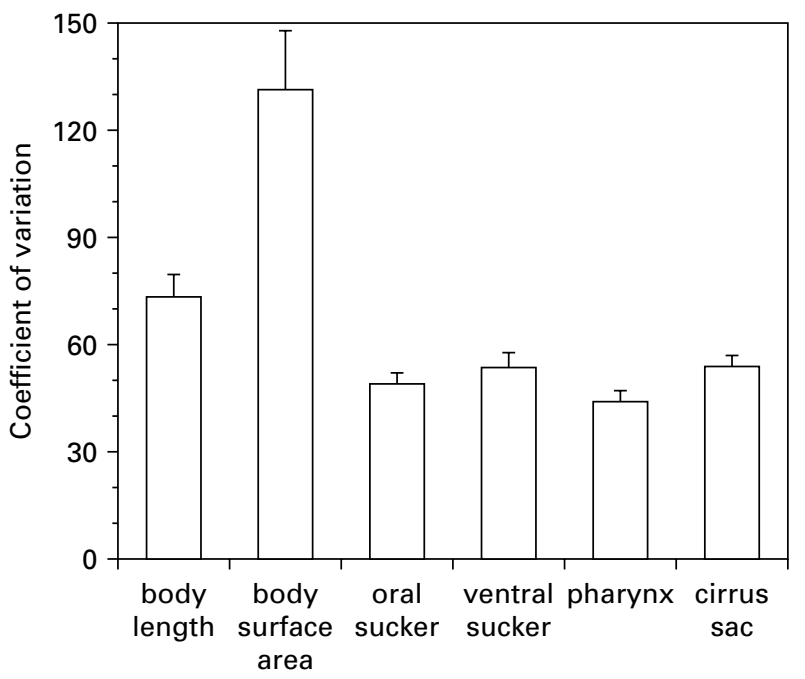

Fig. 1. Coefficients of variation (mean + s.e.) for 6 morphological features among 14 trematode families.

Interspecific variability was greater for some of the traits than for the others (paired $t$-tests, Table 2; Fig. 1). Thus, within families, CV values for body length and in particular body surface area tended to be higher than those for the other 4 traits. There are 


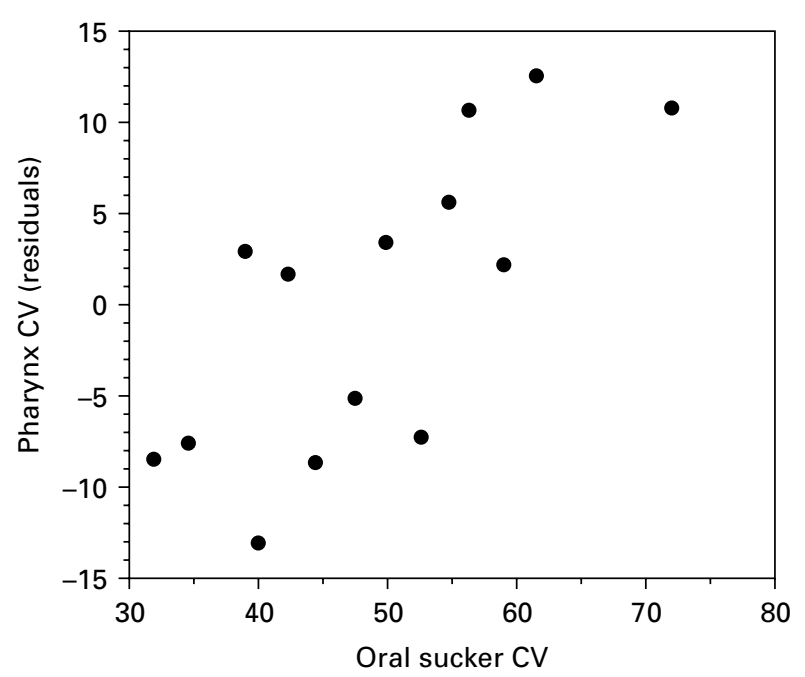

Fig. 2. Relationship between the coefficient of variation $(\mathrm{CV})$ in pharynx length and the $\mathrm{CV}$ in oral sucker size among 14 trematode families. For pharynx length, CV values are residuals of a regression of raw values against the number of species used to estimate $\mathrm{CV}$ in each family.

also some differences in CV among these 4 traits (size of oral sucker, size of ventral sucker, pharynx size, and size of cirrus sac; see Table 2), but these are not as pronounced (Fig. 1).

Across trematode families, there were also some correlations between $\mathrm{CV}$ for one trait and $\mathrm{CV}$ for another trait (Table 2). Thus, not surprisingly, in families where variation in body length is extensive, the same is generally true of variation in body surface area. There was also a strong positive correlation between $\mathrm{CV}$ in pharynx size and $\mathrm{CV}$ in size of the oral sucker (Table 2; Fig. 2), perhaps reflecting the fact that both structures are involved in food acquisition. More intriguingly, $\mathrm{CV}$ in pharynx size was negatively related to $\mathrm{CV}$ in body surface area (Table 2): in families where body area is highly variable across species, the relative size of the pharynx tends not to vary very much.

There were no significant correlations between either of the two measures of family body size, i.e. mean body length and mean body surface area, and $\mathrm{CV}$ values for any of the 6 traits investigated here (all $P>0 \cdot 33$ ). Thus, morphological diversification in all traits was independent of family body size.

There was no difference in $\mathrm{CV}$ values between families exploiting endothermic definitive hosts and those using ectotherms, for any of the 6 traits investigated here (one-way ANOVAs, $P>0.23$ for all). This was confirmed by the analyses based on phylogenetically independent contrasts (one-group $t$-tests, $P>0 \cdot 11$ for all); however, the latter tests were limited in power by the fact that there were at most 5 contrasts per trait on which to perform the analyses. When pooling all contrasts independently of which trait they applied to, there were approximately the

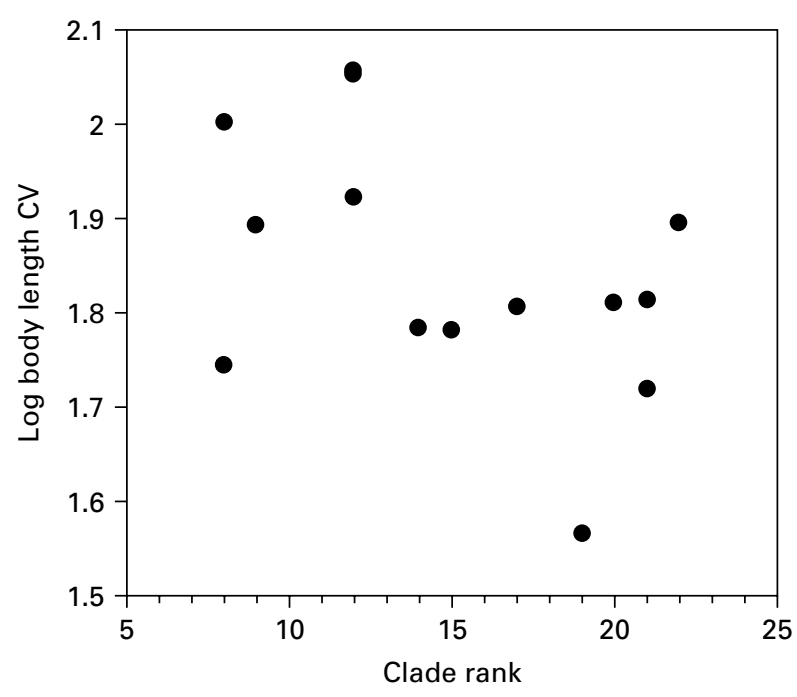

Fig. 3. Relationship between the coefficient of variation (CV) in body length and clade rank across 14 trematode families.

same number of contrasts in which $\mathrm{CV}$ was higher in the family exploiting endothermic hosts as there were in which $\mathrm{CV}$ was higher in the family exploiting ectotherms (16 versus 13 contrasts, respectively).

Families with relatively high $\mathrm{CV}$ in body length tend to be basal (older), i.e. they have a low clade rank, whereas many families with relatively low $\mathrm{CV}$ in body length tend to be more derived (Fig. 3). Similar, though more diffuse, trends are apparent for most other morphological features; however, the conservative likelihood-ratio test shows no significant deviation from a random walk model for any of the 6 morphological traits (all $P>0 \cdot 21$ ). Thus, there is no convincing evidence that older lineages show greater morphological variation than younger, more derived ones.

\section{I S USS I ON}

Several earlier studies have investigated morphological variation in trematode species. Morphometric traits are important features used to differentiate taxa in trematode classification (Gibson et al. 2002; Jones et al. 2005). Therefore, the typical goal of most earlier studies was either to document variation within species resulting from infection intensity (Nollen, 1983; Stillson and Platt, 2007), to compare variation among closely related species in order to better discriminate between them (Kostadinova et al. 2000; Otranto et al. 2007), or to assess the impact of different host species on the morphological development of trematodes and how this may impact on species identification and description (Blankespoor, 1974; Bray and des Clers, 1992; Pérez Ponce de León, 1995). The broader evolutionary patterns of morphological diversification in these parasites have not received attention to date. 
One potential source of background noise in the measurements used here needs to be addressed. The techniques used for fixation and preparation of specimens (i.e. heat or cold fixation, slow or fast fixative, etc.) can lead to some shrinkage, with ensuing effects on the measurements taken on various morphological traits. However, one has to consider the scale of the present study: size variation from the smallest to the largest species within the same family was often 10 to 20 -fold. Any measurement error due to fixation techniques, even if up to $25 \%$ or more, becomes inconsequential across the much larger scales involved in comparisons among different species.

Here, 3 hypotheses regarding the evolutionary diversification of trematode morphology were tested, and no support was found for any of them. First, the degree of morphological variation within a trematode family appears independent of the average body length of species belonging to that family. The reason for the potential importance of body size in the morphological diversification of a lineage is that smaller species may perceive greater habitat heterogeneity than larger species, allowing the former to expand into more niches than the latter. Among the families included in the analysis, however, variation in average body length was not extensive. The family with greatest average body length (Echinostomatidae) was only about 10 times larger in average body length than the family with smallest body length (Microphallidae), and thus all families probably perceived the host intestinal environment at more or less the same scale. Maybe differences of 2 or more orders of magnitude are necessary to detect any effect of body size on morphological diversification.

Second, patterns of morphological diversification appear similar whether endothermic or ectothermic vertebrates are used as definitive hosts. Despite exceptions (i.e. the Dicrocoelidae are overwhelmingly liver and gall bladder parasites), the vast majority (about $98 \%$ out of 386 ) of species included in the present analyses live in the host gastrointestinal tract. Given the greater physical complexity of the endothermic gut wall (Kardong, 2005) and the greater competitive pressures from other parasites within endothermic guts (Bush et al. 1990; Poulin, 1995; Poulin and Morand, 2004), greater phenotypic diversification was expected among trematode lineages exploiting birds or mammals than among those living in teleost fishes, amphibians or reptiles. The fact that this expectation was not met could be due merely to the limited statistical power of the test, since few contrasts were possible. It could also indicate that phylogenetic or developmental constraints acting on trematode morphology are relatively stronger than the external selective pressures associated with different types of hosts. Besides the taxonomic identity of the host, the site of infection within the host may also be associated with rates of diversification. Most trematode taxa included in the present analyses live within the gastrointestinal tract, which allowed for comparisons between host types unconfounded by different sites of infection. However, other trematode families live in blood vessels (e.g. Schistosomatidae), in the liver (Fasciolidae) or in the eyes (Philophthalmidae) of their vertebrate hosts. These other microhabitats may promote greater or lower rates of morphological diversification than the gastrointestinal tract; testing this possibility will be difficult, since colonization of these alternative organs did not occur on many independent occasions during the phylogenetic history of trematodes.

Third, phylogenetically older trematode lineages did not display greater morphological variation than younger, more derived ones. The accumulation of morphological variation over evolutionary time is a simple, passive mechanism to explain differences in phenotypic diversity among different lineages. It does not systematically apply to all taxa, however (Ricklefs, 2004, 2006; Collar et al. 2005). One reason could be, as suggested above, that phylogenetic or developmental constraints acting on trematode morphology serve to dampen any selective push away from the basic family body plan.

So what is the evidence for these constraints? It comes from 2 different results obtained in the present analyses. The first line of evidence is that variation in one trait is not independent of variation in another trait, as shown by the statistical link between the coefficients of variation in the sizes of the pharynx and of the oral sucker. If interspecific variability in one trait is high within a family, it will also be high in the other trait, and vice versa. This association between the two traits may reflect the fact that they evolve in tandem, perhaps because although they play different roles, they both participate in food acquisition. In principle, linkages among different morphological traits can limit variability in any of them over evolutionary time. Although natural selection can overcome developmental constraints (Maynard Smith et al. 1985 ; Beldade et al. 2002), this is not always the case.

The second line of evidence suggesting some sort of constraints acting on morphological diversification is more convincing. Consistently across most of the 14 families included here, variation in body size was more pronounced than variation in the relative sizes of the other morphological features. This relatively large variation in body sizes within families may reflect diversification in body sizes over time, allowing different niches to be colonized. Looking beyond the species included in the present dataset, it is clear that although most trematode species are small-bodied, there is much variability in body sizes across the group, extending over 4 orders of magnitude (Poulin, 1997; Poulin and Morand, 1997). The evolutionary diversification of trematode body sizes is thus not greatly constrained. However, while body size can 
vary, the sizes of other anatomical features relative to body size appear much less labile. Trematode body size can therefore vary widely while the general body architecture of the family is maintained. This could result from stronger developmental or phylogenetic constraints acting on relative sizes of anatomical structures than on overall body size. In other words, the evolution of the body plan may be much more conservative than the evolution of body size in trematodes.

Comparative analyses are intrinsically correlative rather than manipulative, and the causality of observed patterns must be inferred with caution. Ideally, morphological diversification would be investigated experimentally under various selective regimes to provide a robust test of the influence of various forces in determining the degree of phenotypic divergence between related taxa. In the absence of such experimental evidence, the present results suggest that morphological diversification within trematode families proceeds independently of the general size of the worms, of the type of host they use, and of the time since they branched off as a separate lineage. Trematode body size also appears generally much more variable than the relative sizes of anatomical structures associated with attachment, feeding and reproduction, suggesting a conservative body plan. Whether these are characteristics of trematodes only or more broadly of parasitic flatworms could be determined by a similar analysis of cestodes, which have evolved independently from trematodes since they long ago diverged from a common ancestor.

I thank Kim Bryan-Walker for assistance with the compilation of the dataset, and Haseeb Randhawa and two anonymous reviewers for useful comments on an earlier version.

\section{REFERENCES}

Beldade, P., Koops, K. and Brakefield, P. M. (2002). Developmental constraints versus flexibility in morphological evolution. Nature, London 416, 844-847.

Blankespoor, H. D. (1974). Host-induced variation in Plagiorchis noblei Park, 1936 (Plagiorchiidae:

Trematoda). American Midland Naturalist 92, 415-433.

Bray, R. A. and des Clers, S. A. (1992). Multivariate analyses of metrical features in Lepidapedon elongatum (Lebour, 1908) species-complex (Digenea:

Lepocreadiidae) in deep and shallow water gadiform fish of NE Atlantic. Systematic Parasitology 21, 223-232.

Bush, A. O., Aho, J. M. and Kennedy, C. R. (1990). Ecological versus phylogenetic determinants of helminth parasite community richness. Evolutionary Ecology 4, $1-20$.

Carroll, S. B. (2001). Chance and necessity: the evolution of morphological complexity and diversity. Nature, London 409, 1102-1109.

Collar, D. C., Near, T. J. and Wainwright, P. C. (2005). Comparative analysis of morphological diversity: does disparity accumulate at the same rate in two lineages of centrarchid fishes? Evolution 59, 1783-1794.
Felsenstein, J. (1985). Phylogenies and the comparative method. American Naturalist 125, 1-15.

Foote, M. (1997). The evolution of morphological diversity. Annual Review of Ecology and Systematics 28, 129-152.

Galaktionov, K. V. and Dobrovolskij, A. A. (2003). The Biology and Evolution of Trematodes. Kluwer Academic Publishers, Dordrecht, The Netherlands.

Gavrilets, S. and Vose, A. (2005). Dynamic patterns of adaptive radiation. Proceedings of the National Academy of Sciences, USA 102, 18040-18045.

Gibson, D. I., Jones, A. and Bray, R. A. (2002). Keys to the Trematoda, Vol. 1. CABI Publishing, Wallingford, $\mathrm{UK}$.

Jones, A., Bray, R. A. and Gibson, D. I. (2005). Keys to the Trematoda, Vol. 2. CABI Publishing, Wallingford, $\mathrm{UK}$.

Kardong, K. V. (2005). Vertebrates: Comparative Anatomy, Function, Evolution, 4th Edn. McGraw Hill, New York.

Knouft, J. H. and Page, L. M. (2003). The evolution of body size in extant groups of North American freshwater fishes: speciation, size distributions, and Cope's rule. American Naturalist 161, 413-421.

Kostadinova, A., Gibson, D. I., Biserkov, V. and Ivanova, R. (2000). A quantitative approach to the evaluation of the morphological variability of two echinostomes, Echinostoma miyagawai Ishii, 1932 and E. revolutum (Frolich, 1802), from Europe. Systematic Parasitology 45, 1-15.

Lovette, I. J., Bermingham, E. and Ricklefs, R. E. (2002). Clade-specific morphological diversification and adaptive radiation in Hawaiian songbirds. Proceedings of the Royal Society of London, B 269, 37-42.

Maynard Smith, J., Burian, R., Kauffman, S., Alberch, P., Campbell, J., Goodwin, B., Lande, R., Raup, D. and Wolpert, L. (1985). Developmental constraints and evolution. Quarterly Review of Biology 60, 265-287.

Morse, D., Stork, N. E. and Lawton, J. H. (1985). Fractal dimensions of vegetation and the distribution of arthropod body lengths. Nature, London 314, 731-732.

Nollen, P. M. (1983). The effects of crowding on adults of Philophthalmus gralli (Trematoda) grown in chickens. Fournal of Parasitology 69, 196-199.

Norell, M. A. and Novacek, M. J. (1992). The fossil record and evolution: comparing cladistic and paleontological evidence for vertebrate history. Science 255, 1690-1693.

Olson, P. D., Cribb, T. H., Tkach, V. V., Bray, R. A. and Littlewood, D. T. J. (2003). Phylogeny and classification of the Digenea (Platyhelminthes: Trematoda). International fournal for Parasitology 33, 733-755.

O’Meara, B. C., Ané, C., Sanderson, M. J. and Wainwright, P. C. (2006). Testing for different rates of continuous trait evolution using likelihood. Evolution 60, 922-933.

Otranto, D., Rehbein, S., Weig1, S., Cantacessi, C., Parisi, A., Lia, R. P. and Olson, P. D. (2007). Morphological and molecular differentiation between Dicrocoelium dendriticum (Rudolphi, 1819) and Dicrocoelium chinensis (Sudarikov and Ryjikov, 1951) Tang and Tang, 1978 (Platyhelminthes: Digenea). Acta Tropica 104, 91-98. 
Pagel, M. (1997). Inferring evolutionary processes from phylogenies. Zoologica Scripta 26, 331-348.

Pagel, M. (1999). Inferring the historical patterns of biological evolution. Nature, London 410, 877-884.

Pagel, M. (2002). Modelling the evolution of continuously varying characters on phylogenetic trees. In Morphology, Shape and Phylogeny (ed. MacLeod, N. and Foley, P. L.), pp. 269-286. Taylor \& Francis, London, UK.

Pérez Ponce de León, G. (1995). Host-induced morphological variability in adult Posthodiplostomum minimum (Digenea: Neodiplostomidae). Fournal of Parasitology 81, 818-820.

Poulin, R. (1995). Phylogeny, ecology, and the richness of parasite communities in vertebrates. Ecological Monographs 65, 283-302.

Poulin, R. (1997). Egg production in adult trematodes: adaptation or constraint? Parasitology 114, 195-204.

Poulin, R. (2007). Evolutionary Ecology of Parasites, 2nd Edn. Princeton University Press, Princeton, USA.

Poulin, R. and Morand, S. (1997). Parasite body size distributions: interpreting patterns of skewness. International fournal for Parasitology 27, 959-964.

Poulin, R. and Morand, S. (2004). Parasite Biodiversity. Smithsonian Institution Press, Washington, D.C., USA.
Ricklefs, R. E. (2004). Cladogenesis and morphological diversification in passerine birds. Nature, London 430 , 338-341.

Ricklefs, R. E. (2006). Time, species, and the generation of trait variance in clades. Systematic Biology 55, 151-159.

Ritchie, M. E. and Olff, H. (1999). Spatial scaling laws yield a synthetic theory of biodiversity. Nature, London 440, 557-560.

Siemann, E., Tilman, D. and Haarstad, L. (1996). Insect species diversity, abundance and body size relationships. Nature, London 380, 704-706.

Stillson, L. L. and Platt, T. R. (2007). The crowding effect and morphometric variability in Echinostoma caproni (Digenea: Echinostomatidae) from ICR mice. Fournal of Parasitology 93, 242-246.

Wainwright, P. C. (2007). Functional versus morphological diversity in macroevolution. Annual Review of Ecology, Evolution and Systematics 38, 381-401.

Warheit, K. I., Forman, J. D., Losos, J. B. and Miles, D. B. (1999). Morphological diversification and adaptive radiation: a comparison of two diverse lizard clades. Evolution 53, 1226-1234. 